Original Article

\title{
Cytogenetic features in primary myelodysplastic syndrome Egyptian patients
}

\author{
Yasser Elnahass ${ }^{\mathrm{a}}$, Lamiaa Youssif ${ }^{\mathrm{b}, *}$ \\ ${ }^{a}$ Department of Clinical Pathology, National Cancer Institute, Cairo University, Cairo, Egypt \\ ${ }^{\mathrm{b}}$ Department of Molecular Diagnostics, Genetic Engineering and Biotechnology Research Institute, University of Sadat City, Sadat City, Menoufia Province, Egypt
}

\section{A R T I C L E I N F O}

\section{Article history:}

Received 8 September 2017

Revised 5 January 2018

Accepted 6 February 2018

Available online 7 February 2018

\section{Keywords:}

MDS

Gender

Chromosomal abnormalities

$-5 / 5 q-$

MDS-MLD

MDS-EB-II

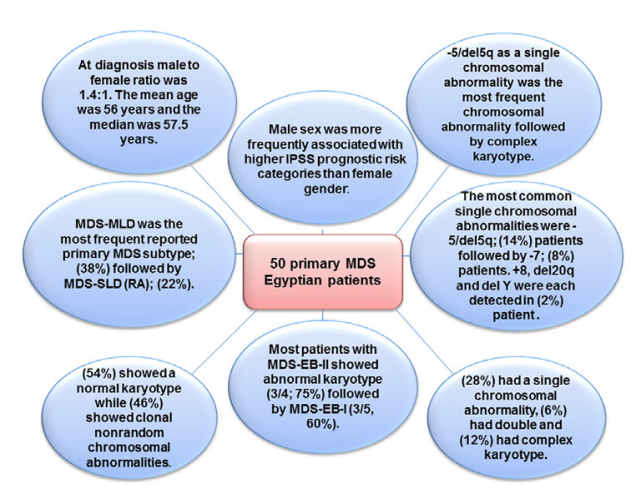

\footnotetext{
Peer review under responsibility of Cairo University.

* Corresponding author.

E-mail address: lamiayoussif1@gmail.com (L. Youssif).
} 
information in establishing accurate diagnosis and male gender is an important predisposing factor that can predict worse prognosis in MDS patients.

(C) 2018 Production and hosting by Elsevier B.V. on behalf of Cairo University. This is an open access article under the CC BY-NC-ND license (http://creativecommons.org/licenses/by-nc-nd/4.0/).

\section{Introduction}

Myelodysplastic syndromes (MDS) are acquired, neoplastic disorders of hematopoietic stem cells (HSCs) characterized by ineffective and dysplastic myeloid cell differentiation and a high rate of progression to acute myeloid leukemia (AML) [1,2]. The bone marrow (BM) in MDS is hypercellular with disordered growth and maturation and clonal proliferation of abnormal cells. Peripheral blood (PBL) cytopenias are due to insufficient hematopoiesis, affecting myeloid, erythroid and megakaryocyte lineages. The disease course is highly variable, ranging from indolent to aggressive with progression to AML [3].

MDS arise de novo, but $10 \%$ patients may acquire MDS as a consequence of previous radio/chemo therapy for other cancers $[3,4]$. The median age of MDS patients at diagnosis is $65-70$ years. $<10 \%$ of patients are younger than 50 years with an incidence about four cases per 100,000 population. This disorder shows a slight male predominance except for isolated $5 q$ deletion in which women predominate. The pathophysiology is a multistep process involving cytogenetic changes, gene mutations, or both. Diagnosis is based mainly on examination of peripheral blood and BM displaying cytopenias and hypercellular marrow with dysplasia, with or without excess of blasts [5].

The classification of MDS is continuously evolving and prognosis is largely dependent on the presence of chromosomal abnormalities [6]. Every new validated classification reflects better understanding of the disease, its pathogenesis and prognosis [7]. An International Prognostic Scoring System (IPSS) and a World Health Organization (WHO) classification have now been devised, which assess the type and extent of marrow cytogenetic abnormality and the cell lines affected [8]. The WHO is now the recommended classification system [9]. The original IPSS has now been replaced by a revised version [10]. The WHO 2016 classification revision of myeloid neoplasms and acute leukemia edition includes MDS with single lineage dysplasia (MDS-SLD), MDS with multilineage dysplasia (MDS-MLD), MDS with ring sideroblasts (MDS-RS), MDS with excess blasts (MDS-EB-1 and 2), MDS with isolated del (5q) and MDS unclassifiable (MDS-U) [9].

MDS frequently has unbalanced translocations, and deletions, implicating loss of function or haplo-insufficiency of tumor suppressor genes [11]. BM chromosomal abnormalities occur in almost half of de novo cases [12]. Deletions are the most common cytogenetic abnormalities in de novo MDS. The gain can arise in both primary and therapy-related MDS. Balanced translocations are uncommon in patients with MDS and are mainly related to unfavorable prognosis [11]. The cytogenetic abnormalities recorded in the 2008 WHO classification [13] continue to exist MDS-defining in a cytopenic patient, even in the absence of diagnostic morphologic dysplasia. Del (5q) remains as the only genetic abnormality that defines a specific MDS subtype. One of the biggest challenges confronting hematologists is how to separate MDS from reactive cases of cytopenia and dysplasia. Despite the fact that cytogenetic findings are not used to outline specific subtypes of MDS, they may be strongly correlated with prognosis and may help in establishing diagnosis in unconfirmed MDS cases as well as MDS unclassifiable thus, a complete BM karyotype remains a critical test in any newly diagnosed MDS patient [9].

The present study was undertaken to discover the most frequent cytogenetic abnormalities in primary MDS Egyptian patients diagnosed by PBL and BM morphology and to correlate abnormal karyotypic findings with different MDS WHO subtypes in addition to clarify the association between gender and different IPSS prognostic risk categories.

\section{Patient and methods}

Fifty de novo MDS Egyptian patients were included. BM aspiration and PBL samples were collected at the time of diagnosis at National Cancer Institute (NCI), Cairo University and were sent for karyotype and analysis at the laboratory of Genetic Engineering and Biotechnology Research Institute (GEBRI), Sadat City University at the period between October 2010 and December 2016. Diagnosis of MDS was based on full history taking, clinical assessment and laboratory investigations including complete blood count, bone marrow aspirate with iron stain, and conventional banding analysis (karyotype). At the time of analysis, a second revision was made and patients were classified according to the 2016 revision to the World Health Organization (WHO) classification of myeloid neoplasms [9]. All patients gave written informed consent. The study was approved from the Institutional Research Board of GEBRI.

\section{Prussian blue reaction (Perls' stain for iron)}

Prussian blue reaction was assessed on BM smears. Ferric iron deposits in tissue then react with soluble ferrocyanide in the stain, to form insoluble Prussian blue dye in situ, then visualized microscopically as blue or purple deposits, within cells. In brief, BM aspirate was spread on to glass slides, air dried, and fixed with methanol. Equal volume of $2 \%$ of potassium ferrocyanide and $2 \%$ hydrochloric acid solution were mixed in staining jar and slides are immersed in the solution for 15-20 min. then removed and rinsed with distilled water. Counterstaining with saffranin for 30 s. then allowed to dry and examined [14].

\section{Conventional banding analysis (CBA)}

Chromosomal banding analysis was performed by G-banding techniques [15]. Unstimulated BM cells were cultured in double (2 parallel cultures for each patient) for $16 \mathrm{~h}$ in Roswell Park Memorial Institute (RPMI) 1640 medium with L-glutamine and 25 mM HEPES (Cambrex Bioproducts, Belgium) supplemented with $15 \%$ Fetal calf serum (FCS) (Cambrex Bioproducts, Belgium) and penicillin/streptomycin mixture 1000 u Pen/10,000 ug strept (Cambrex Bioproducts, Belgium) (complete medium). On day 2, cells were pulsed with $20 \mu \mathrm{l}$ of $10 \mu \mathrm{g} / \mathrm{ml}$ colcemid (GIBCO) for $25 \mathrm{~min}$. and treated with hypotonic $0.075 \mathrm{M}$ potassium chloride (KCL) solution for $30 \mathrm{~min}$. at $37^{\circ} \mathrm{C}$. Cells were then fixed in methanol: acetic acid (3:1). At least 20 metaphase cells were analyzed using Cytovision Software (Applied Biosystem) for each sample after trypsinization and staining slides with Giemsa. Karyotypes were described according to the International System for Human Cytogenetic Nomenclature, 2013 [16]. Cytogenetic abnormalities used to define MDS in cytopenic patients were according to WHO, 2016 criteria.

\section{PBL and BM morphology}

Morphological assessment for diagnosing MDS, defining cytopenias and rating of dysplasia were done and revised according to WHO 2016 criteria [9]. 
Treatment

According to revised international prognostic scoring system (IPSS-R) [10], low risk patients received supportive care aiming to improve quality of life including red cell and platelet transfusions, and antibiotic/antifungal therapy when needed in addition to iron chelation therapy. Erythropoietin and granulocyte-colony stimulating factors (G-CSF) were used to treat anemia and neutropenia respectively. Lenalidomide therapy was given to all $5 q-$ patients. Elderly patients with MDS-EB-II received hypomethylating agents like azacitidine or decitabine if available, whereas younger patients with MDS-EB-II were treated with AML-like induction therapy (e.g. $3+7$ ) and were sent for hematopoietic stem cell transplantation after achieving complete remission if an HLA matched donor was available.

\section{Statistical analyses}

Statistical analysis was performed using the Statistical Package for the Social Sciences (version 20; SPSS, Inc., Chicago, IL, USA). Numerical data became offered as the mean \pm SD or median and range as appropriate. Qualitative records have been expressed as frequency and percentage.

\section{Results}

Fifty primary MDS Egyptian patients at diagnosis were included; 29 males (58\%) and 21 females (42\%). Median age was 57.5 years $(20-85)$ with a mean of $56 \pm 12.03$. 11 patients $(22 \%)$ were diagnosed MDS-SLD, 2 (4\%) MDS-RS-SLD, 19 (38\%) were MDS-MLD, 5(10\%) were MDS-EB-1, 4 (8\%) were MDS-EB-2, 3 cases (6\%) were MDS associated with isolated $\operatorname{del}(5 q)$, and 6 patients (12\%) were MDS unclassifiable (MDS-U). 27 patients (54\%) had normal karyotype and 23 patients (46\%) had abnormal karyotype (Table 1).

Table 1

Patients characteristics.

\begin{tabular}{|c|c|c|}
\hline Age (years) & $\begin{array}{l}\text { Mean } \pm \text { Std. Deviation } \\
\text { Median (range) }\end{array}$ & $\begin{array}{l}56 \text { years } \pm 12.03 \\
57.5 \text { years }(20-85)\end{array}$ \\
\hline \multirow[t]{2}{*}{ Gender (n, \%) } & Male & $29(58 \%)$ \\
\hline & Female & $21(42 \%)$ \\
\hline \multirow[t]{2}{*}{ Hemoglobin (gm/dl) } & Mean \pm Std. Deviation & $7.5 \pm 1.55$ \\
\hline & Median (range) & $7.4(4-10.7)$ \\
\hline \multirow{2}{*}{$\begin{array}{l}\text { Total leukocytic count } \\
\qquad\left(\times 10^{9} / \mathrm{L}\right)\end{array}$} & Mean \pm Std. Deviation & $4.0 \pm 2.698$ \\
\hline & Median (range) & $2.65(0.8-14.3)$ \\
\hline \multirow{2}{*}{ Platelet count $\left(\times 10^{9} / \mathrm{L}\right)$} & Mean \pm Std. Deviation & $98 \pm 96.537$ \\
\hline & Median (range) & $57.5(8-430)$ \\
\hline \multirow[t]{3}{*}{ PBL cytopenias $(n, \%)$} & Unicytopenia & $16(32 \%)$ \\
\hline & Bicytopenia & $15(30 \%)$ \\
\hline & Pancytopenia & $19(38 \%)$ \\
\hline \multirow{3}{*}{$\begin{array}{l}\text { Bone marrow cellularity } \\
\qquad(n, \%)\end{array}$} & Hypercellular marrow & $32(64 \%)$ \\
\hline & Normocellular marrow & $12(24 \%)$ \\
\hline & Hypocellular marrow & $6(12 \%)$ \\
\hline \multirow[t]{3}{*}{ BM blasts $(n, \%)$} & $<5 \%$ & $41(82 \%)$ \\
\hline & $5 \%-9 \%$ & $5(10 \%)$ \\
\hline & $10 \%-19 \%$ & $4(8 \%)$ \\
\hline \multirow[t]{3}{*}{ Iron storage in $\mathrm{BM}(n, \%)$} & Increased & $39(78 \%)$ \\
\hline & Normal & $8(16 \%)$ \\
\hline & Reduced & $3(6 \%)$ \\
\hline \multirow[t]{7}{*}{ MDS subtypes $(n, \%)$} & MDS-SLD (RA) & $11(22 \%)$ \\
\hline & MDS-RS-SLD & $2(4 \%)$ \\
\hline & MDS-MLD & $19(38 \%)$ \\
\hline & MDS-EB-I & $5(10 \%)$ \\
\hline & MDS-EB-II & $4(8 \%)$ \\
\hline & Isolated del (5q) & $3(6 \%)$ \\
\hline & MDS-U & $6(12 \%)$ \\
\hline \multirow[t]{2}{*}{ Karyotype } & Normal & $27(54 \%)$ \\
\hline & Abnormal & $23(46 \%)$ \\
\hline
\end{tabular}

With exclusion of MDS associated with isolated del (5q) subtype, patients with MDS-EB-II had the highest frequency of chromosomal abnormality 3/4 (75\%) among primary MDS Egyptian patients (Table 2). Table 2 also shows the incidence of the different chromosomal abnormalities in relation to the 2016 WHO classification of MDS.

Among 50 patients with primary MDS; 14/50 (28\%) had single Chromosomal abnormality, 3/50 (6\%) had double chromosomal abnormality and 6/50 (12\%) had complex karyotype. The most common single chromosomal abnormalities were $-5 /$ del $(5 q)$ found in $7 / 50$ patients (14\%), -7 in $4 / 50$ patients $(8 \%),+8$, del $20 \mathrm{q}$ and $-\mathrm{Y}$ were found in $1 / 50$ patient (2\%) each (Table 3; Figs. 1 and 2).

Table 4 shows different risk classification categories for the 50 primary MDS patients according to IPSS-R.

Regarding gender, abnormal karyotype was slightly higher in males $14 / 29$ (48.3\%) than females $9 / 21$ (42.9\%). Mean $\mathrm{Hb}$ in males and females was comparable $(7.44 \pm 1.4$ vs. $7.57 \pm 1.70$ $\mathrm{gm} / \mathrm{dl})(P=0.588)$. However, males showed a trend to have a lower TLC $3.55 \pm 2.08 \times 10^{9} / \mathrm{L}$ vs. $4.60 \pm 3.32 \times 10^{9} / \mathrm{L}$ in females $(P=0.073)$. Additionally, the mean platelet count in males was significantly lower than females $71 \pm 50.146 \times 10^{9} /$ L vs. $134 \pm 1$ $30.205 \times 10^{9} / \mathrm{L}(P=0.006)$.

When distributing gender into different IPSS risk categories; males were more frequently associated with intermediate and high risk categories while female patients were in low risk (Tables 5 and 6).

\section{Discussion}

MDS shows a characteristic genetic profile with an overweighing of unbalanced abnormalities. Cytogenetic abnormalities are major determinants of diagnosis and prognosis in MDS.

In the present study, male to female ratio was $1.4: 1$, which is consistent with reports from European and Asian regions [17]. The mean age was 56 years and the median was 57.5 years, which was in line with the mean age 55 years that was previously reported in Egyptian patients with MDS [18], and comparable with median age 60 years in Tunisian [19] and 59 years in Pakistani patients [17]. However, the age was lower (67 years) than that recorded in USA patients [20], and higher (45 years) than that reported in Chinese [21] and in Indian (42 years) patients [22]. We agree with the previous suggestion that the age difference at diagnosis between world regions was due to uncover possible hereditary, genetic, immunologic, infectious, and other environmental factors such as organic solvents, pesticides, and radiation differences between different populations in different countries [23].

According to WHO 2016, MDS-MLD in our study was the most frequent reported primary MDS subtype (38\%) followed by MDSSLD (RA) (22\%) which was in agreement with previous reports from Egyptian MDS patients [18] while MDS-MLD was the most frequent subtype among German patients (27.6\%) followed by MDSEB-II (20.6\%) [24], in US patients (32.2\%) followed by MDS-EB-I (19.7\%) [20], in Chinese patients (44\%) followed by MDS-EB-I (19\%) [21], and in Pakistani patients (52.1\%) followed by MDSEB-II (23.9\%) [17]. This finding was in contrast with Indian primary MDS patients as MDS-SLD was the most frequent MDS subtype (37.5\%) followed by MDS-EB-I (17.5\%) [22].

In our study, the mean number of metaphases analyzed was 20 , which is consistent with the criteria for high-quality cytogenetic studies in MDS. By contrast, the frequencies of chromosomal abnormalities previously reported by others were often based on analyses with fewer $(>10)$ metaphases thus, increasing the probability of missing an anomaly [22]. Clonal nonrandom cytogenetic 
Table 2

Cytogenetic profile of 50 MDS patients.

\begin{tabular}{|c|c|c|c|c|c|c|}
\hline Primary MDS types & $\begin{array}{l}\text { Normal } \\
\text { karyotype } \\
(\mathrm{n}, \%)\end{array}$ & Normal karyotype & $\begin{array}{l}\text { Age } \\
\text { (years) }\end{array}$ & $\begin{array}{l}\text { Abnormal } \\
\text { karyotype } \\
(\mathrm{n}, \%)\end{array}$ & Abnormal karyotype & $\begin{array}{l}\text { Age } \\
\text { (years) }\end{array}$ \\
\hline \multirow[t]{8}{*}{ MDS-SLD $(n=11)$} & \multirow[t]{8}{*}{$8(72.7 \%)$} & $46, \mathrm{XY}[17]$ & 61 & \multirow[t]{8}{*}{$3(27.3 \%)$} & $45, \mathrm{XY},-7[4]$ & 37 \\
\hline & & $46, \mathrm{XY}[17]$ & 62 & & 46, XX, del 3q21, del 5(q14q33) [5] & 35 \\
\hline & & $46, \mathrm{XY}[17]$ & 60 & & $45, \mathrm{XX},-7[5]$ & 44 \\
\hline & & $46, \mathrm{XX}[17]$ & 52 & & & \\
\hline & & $46, \mathrm{XY}[17]$ & 50 & & & \\
\hline & & $46, \mathrm{XY}[17]$ & 54 & & & \\
\hline & & $46, \mathrm{XX}[17]$ & 56 & & & \\
\hline & & $46, \mathrm{XX}[17]$ & 59 & & & \\
\hline \multirow[t]{2}{*}{ MDS-RS-SLD $(n=2)$} & \multirow[t]{2}{*}{$2(100 \%)$} & $46, \mathrm{XY}[17]$ & 58 & \multirow[t]{2}{*}{ Zero $(0 \%)$} & \multirow[t]{2}{*}{-ー-ー-ー- } & \multirow[t]{2}{*}{-} \\
\hline & & $46, \mathrm{XY}[17]$ & 63 & & & \\
\hline \multirow[t]{10}{*}{ MDS-MLD ( $\mathrm{n}=19)$} & \multirow[t]{10}{*}{$9(47.4 \%)$} & $46, \mathrm{XX}[17]$ & 50 & \multirow[t]{10}{*}{$10(52.6 \%)$} & $45, X Y,-5[5]$ & 67 \\
\hline & & $46, \mathrm{XY}[17]$ & 62 & & $44, X,-X,-5[5]$ & 51 \\
\hline & & $46, \mathrm{XY}[17]$ & 81 & & $47, \mathrm{XY},+8[6]$ & 63 \\
\hline & & $46, \mathrm{XX}[17]$ & 48 & & $45, \mathrm{XY},-5[8]$ & 77 \\
\hline & & $46, \mathrm{XX}[17]$ & 64 & & $45, \mathrm{XX},-7[8]$ & 72 \\
\hline & & $46, \mathrm{XY}[17]$ & 41 & & $46, \mathrm{XY}$, del 20q [3] & 85 \\
\hline & & $46, \mathrm{XX}[17]$ & 59 & & $45, \mathrm{X},-\mathrm{Y}[5]$ & 46 \\
\hline & & $46, \mathrm{XY}[17]$ & 58 & & $45, \mathrm{XY},-7[6]$ & 75 \\
\hline & & $46, \mathrm{XX}[17]$ & 57 & & $47, \mathrm{XY},-5,+11,+21[3]$ & 59 \\
\hline & & & & & $47, \mathrm{XY},+3,-5,+19[4]$ & 41 \\
\hline \multirow[t]{3}{*}{ MDS-EB-I $(n=5)$} & \multirow[t]{3}{*}{$2(40 \%)$} & 46, XY [17] & & \multirow[t]{3}{*}{$3(60 \%)$} & $47, \mathrm{XX},-7,+18,+21[8]$ & 44 \\
\hline & & $46, \mathrm{XY}[17]$ & 60 & & 46, XY, del5(q14q33) [3] & 53 \\
\hline & & & 53 & & $48, \mathrm{XX},+8,+11,+19,-22[3]$ & 42 \\
\hline \multirow[t]{3}{*}{ MDS-EB-II $(n=4)$} & \multirow[t]{3}{*}{$1(25 \%)$} & \multirow[t]{3}{*}{$46, \mathrm{XX}[17]$} & 55 & \multirow[t]{3}{*}{$3(75 \%)$} & 47, XY, del13(q14q22), -5, +8, +17 [4] & 20 \\
\hline & & & & & $44, \mathrm{XY}, \operatorname{del} 7(\mathrm{q} 22 \mathrm{q} 31),-14,-20[4]$ & 51 \\
\hline & & & & & $46, \mathrm{XY},-7,+21[5]$ & 47 \\
\hline \multirow{3}{*}{$\begin{array}{l}\text { MDS associated with isolated } \\
\quad \text { del }(5 q)(n=3)\end{array}$} & \multirow[t]{3}{*}{ ZERO (0\%) } & \multirow[t]{3}{*}{-----------} & - & \multirow[t]{3}{*}{$3(100 \%)$} & $46, \mathrm{XX}, \operatorname{del} 5$ (q31q33) [6] & 74 \\
\hline & & & & & $46, \mathrm{XX}, \operatorname{del} 5(\mathrm{q} 31 \mathrm{q} 33)[7]$ & 60 \\
\hline & & & & & $46, \mathrm{XX}, \operatorname{del} 5(\mathrm{q} 31 \mathrm{q} 33)[4]$ & 65 \\
\hline \multirow[t]{5}{*}{ MDS-U $(n=6)$} & \multirow[t]{5}{*}{$5(83.3 \%)$} & $46, \mathrm{XX}[17]$ & 50 & \multirow[t]{5}{*}{$1(16.7 \%)$} & \multirow[t]{5}{*}{$45, \mathrm{XY},-5[4]$} & \multirow[t]{5}{*}{43} \\
\hline & & $46, \mathrm{XX}[17]$ & 58 & & & \\
\hline & & $46, \mathrm{XY}[17]$ & 61 & & & \\
\hline & & $46, \mathrm{XX}[17]$ & 61 & & & \\
\hline & & $46, \mathrm{XY}[17]$ & 56 & & & \\
\hline
\end{tabular}

Table 3

Major cytogenetic features in 50 primary MDS patients.

\begin{tabular}{ll}
\hline Chromosomal abnormality & No (\%) \\
\hline Normal karyotype & $27(54 \%)$ \\
$-5 /$ del $(5 q)$ & $7(14 \%)$ \\
-5 & $3(6 \%)$ \\
Del (5q) & $4(8 \%)$ \\
-7 & $4(8 \%)$ \\
+8 & $1(2 \%)$ \\
$20 q-$ & $1(2 \%)$ \\
$-Y$ & $1(2 \%)$ \\
Double chromosomal abnormality & $3(6 \%)$ \\
Complex karyotype & $6(12 \%)$ \\
\hline
\end{tabular}

abnormalities in our patients were identified in 23/50 patients (46\%) that was comparable to that described in primary MDS patients from Tunisia (51\%) [19], Germany (49.8\%) [24], India (47.5\%) [22] and Pakistan (42.3\%) [17], but lower than that found in Chinese series (67.5\%) [21]. In the current study, MDS-EB-II had the highest frequency of chromosomal abnormality (75\%) higher than that reported from Pakistan (58.8\%) [17], USA (62\%) [20], and from India (67\%) [22]. In contrast to Chinese patients as MDS-U had the highest frequency of chromosomal abnormality [21] while in our study, MDS-U had the lowest frequency of cytogenetic abnormalities after MDS-RS-SLD. One of our patients with no dysplastic morphological criteria has been diagnosed as MDS based on presence of -5 . This patient had pancytopenia and BM blasts $<5 \%$ which underscores the importance of applying WHO criteria. Twelve \% of our patients had complex cytogenetics which was lower than reports from Germany (14\%) [24], China (15.1\%) [21], Pakistan (15.5\%) [17], US (17.6\%) [20], but higher than that reported from Tunisia (8\%) [19].

In this study, abnormalities of chromosome 5 (-5/del5q) as a single chromosomal abnormality was the most frequent chromosomal abnormality (14\%) followed by complex karyotype (12\%). This was in agreement with reports from Tunisian MDS patients (13\%) but in contrast to our study it was followed by $-7(8 \%)$ [19]. Similar findings were reported previously in Germany, Austria [24,25], Switzerland $[19,26]$ and Greece $[19,27]$ as $-5 /$ del (5q) was stated to be the most frequent chromosomal abnormality in primary MDS patients but with slightly higher frequencies than us. Pozdnyakova et al. [20] reported the same results from US patients but with a lower frequency (5.9\%). In contrast, Toyame et al. [28], Matsushima et al. [29] and Matsuda et al. [30] found that Japanese patients had a much lower frequency of del (5q) in the east ( $2 \%, 1.5 \%$ and $2.9 \%$ respectively). Li et al. also reported that $-5 /$ del $(5 q)$ had a lower frequency among Chinese patients $(5.1 \%)$ [21]. Monosomy 7 was found as a single chromosomal abnormality in $8 \%$ of our primary MDS patients which was similar that detected by others ( $8 \%$ ) from Tunisian patients [19] while it was lower than that reported by Chaubey et al. (15\%) in forty Indian MDS patients and was the most common chromosomal abnormality [22]. Trisomy 8 as a single chromosomal abnormality was detected in only (2\%) of our primary MDS patients which was in agreement with reports of $3 \%$ from Tunisian study [19] while it was the commonest single chromosomal abnormality in Pakistani and Chinese patients with primary MDS (9.9\% and $19.1 \%$, respectively) [17,21]. 


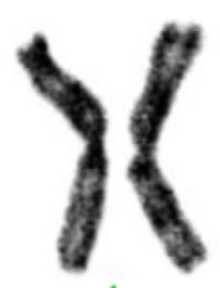

1

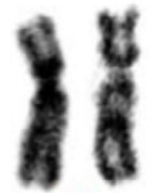

6

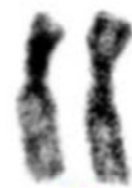

7

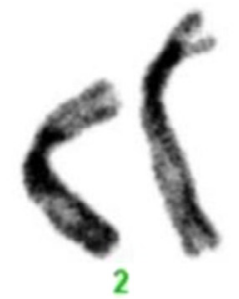

2

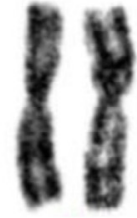

3

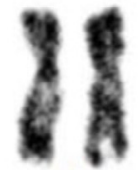

8

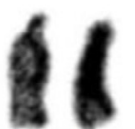

14

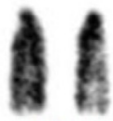

15

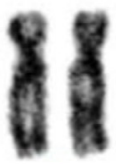

9

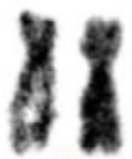

10

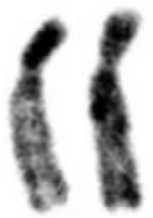

4

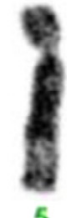

5

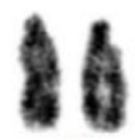

13
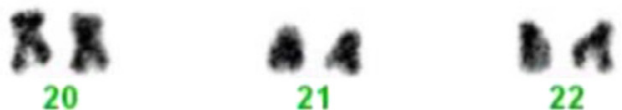

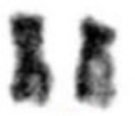

16

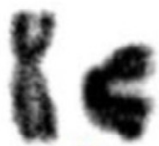

11

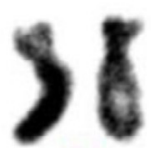

12

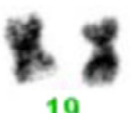

19
20
21

22

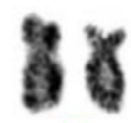

17

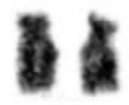

18

Fig. 1. G-banded karyotype showing $45, \mathrm{XY},-5$.

$-\mathrm{Y}$ as a single chromosomal abnormality was detected in only one patient 46 years old which was in agreement with reports on Tunisian primary MDS patients [19] as loss of chromosome $\mathrm{Y}$ was found in one 30 years old patient and reported by Rashid et al. in two patients [17]. Detection of chromosomal abnormalities in the BM implicates malignant or premalignant condition. Loss of chromosome $\mathrm{Y}$ as the only cytogenetic abnormality is one exception to the rule, as it may be visible within the BM of healthy aged individuals. The frequencies of loss in normal and MDS patients are (7.7\% and $1.7 \%$, respectively) [31]. Loss of Y chromosome may represent a normal age related process or an abnormal MDS clone. But, even if it represents an abnormal clone, it is unsure whether is related to disease pathogenesis or not although associated with a better prognosis and survival $[17,31]$.

In the present study we found that there was a large agreement among our frequencies of some chromosomal abnormalities especially $-5 /$ del $(5 q),-7$ and +8 and frequencies reported from Tunisian patients which was slightly lower than frequencies that reported from European series [19]. The reason of this slight difference may be due to the fact that none of our patients had complementary interphase Fluorescence In Situ Hybridization (iFISH), or to real difference, remains to be elucidated.
In this study, all 5q- patients were females who carried a lower risk and resulted in significantly higher platelet count in females versus males. Male gender was more frequently associated with higher IPSS risk categories. Although the reason is not completely understood but it largely agrees with others who proved a faster molecular aging in males that simultaneously increases probabilities for abnormal genetic and epigenetic programs [32,33]. This finding denotes that gender could be added as an important determinant of MDS outcome.

Pathogenesis of MDS in our region is still poorly understood. Environmental, biological, hereditary, genetic and occupational factors are surely different from Western countries and could induce mechanisms that are associated with diverse karyotypes and variable frequency of chromosomal abnormalities [22]. Genetic load and degree of exposure to etiological agents in various countries owing to socio-economic standards might explain the differences in frequency of MDS subtypes, age at diagnosis and incidence of clonal nonrandom chromosomal abnormalities among our patients and that reported previously from other populations. We have a large agreement with Komorkji [23] that MDS may behave differently where the sun rises and where the sun sets. But it is appearing to occur some similarities in primary MDS characteristics among Egyptian, Tunisian and European patients. 

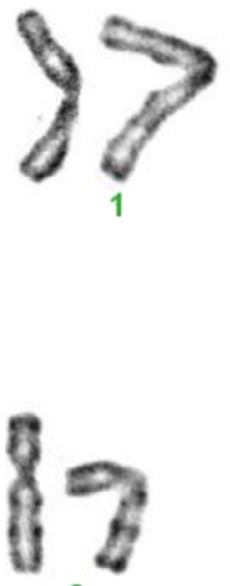

6

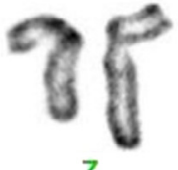

7

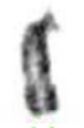

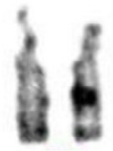

13
14

4

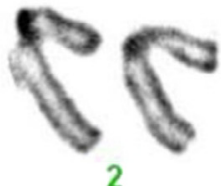

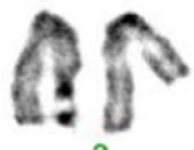

3

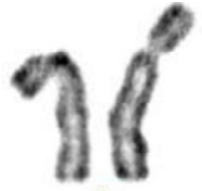

4

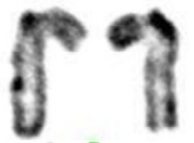

5

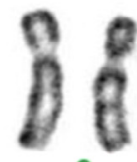

8

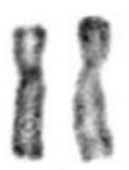

9

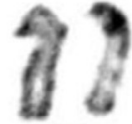

10

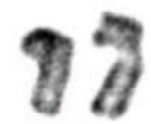

11

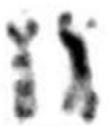

12

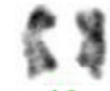

19

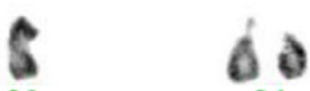

20

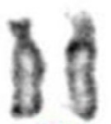

15

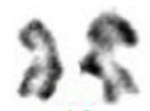

16

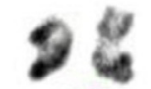

17

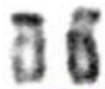

18
Table 4

Risk classification according to IPSS-R for 50 primary MDS patient.

\begin{tabular}{lll}
\hline Risk score & Risk categories & Patients $(\mathrm{n}, \%)$ \\
\hline$\leq 1.5$ & Very low & $1(2 \%)$ \\
$>1.5-3$ & Low & $24(48 \%)$ \\
$>3-4.5$ & Intermediate & $9(18 \%)$ \\
$>4.5-6$ & High & $9(18 \%)$ \\
$>6$ & Very high & $7(14 \%)$ \\
\hline
\end{tabular}

Table 5

Distribution of gender in different IPSS risk categories.

\begin{tabular}{lll}
\hline Risk category & Males $(\mathrm{n}=29)$ & Females $(\mathrm{n}=21)$ \\
\hline Low (very low/low) & $12(41.4 \%)$ & $13(61.9 \%)$ \\
Intermediate & $6(20.7 \%)$ & $3(14.3 \%)$ \\
High (very high/high) & $11(37.9 \%)$ & $5(23.8 \%)$ \\
\hline
\end{tabular}

Table 6

Association between gender and IPSS risk categories.

\begin{tabular}{lll}
\hline Risk category & Males & Females \\
\hline Low (very low/low) $(\mathrm{n}=25)$ & $12(48 \%)$ & $13(52 \%)$ \\
Intermediate $(\mathrm{n}=9)$ & $6(66.7 \%)$ & $3(33.3 \%)$ \\
High (very high/high) $(\mathrm{n}=16)$ & $11(68.8 \%)$ & $5(31.25 \%)$ \\
\hline
\end{tabular}

\section{Conclusions}

This study establishes large similarities in cytogenetic features of MDS Egyptian patients with Tunisian and European patients. $-5 /$ del5q- as a single chromosomal abnormality was the most frequent chromosomal abnormality among our patients followed by complex karyotype. In addition, our study reveals that male sex is more frequently associated with higher IPSS prognostic risk categories than female gender. Cytogenetic abnormalities in combination with gender can provide useful information to clinicians in predicting prognosis and making plans for effective treatment.

\section{Conflict of interest}

The authors have declared no conflict of interest.

\section{References}

[1] Krönke J, Fink EC, Hollenbach PW, MacBeth KJ, Hurst SN, Udeshi ND, et al Lenalidomide induces ubiquitination and degradation of CK1 $\alpha$ in $\operatorname{del}(5 q)$ MDS. Nature 2015;523(7559):183-8.

[2] Chesnais V, Renneville A, Toma A, Lambert J, Passet M, Dumont F, et al. Effect of lenalidomide treatment on clonal architecture of myelodysplastic syndromes without 5q deletion. Blood 2016;127:749-60.

[3] Barzi A, Sekeres MA. Myelodysplastic syndromes: a practical approach to diagnosis and treatment. Cleve Clin J Med 2010;77(1):37-44. 
[4] Look A. Molecular pathogenesis of MDS. Hematology Am Soc Hematol Educ Program 2005;1:156-60.

[5] Adès L, Raphael I, Fenaux P. Myelodysplastic syndromes. Lancet 2014;383:2239-52.

[6] Maniatis A. Progress in the treatment of myelodysplastic syndromes. Blood Transfus 2008;6(4):180-1.

[7] Komrokji RS, Bennett JM. Evolving classifications of the myelodysplastic syndromes. Curr Opin Hematol 2007;14(2):98-105.

[8] Bejar R, Steensma DP. Recent developments in myelodysplastic syndromes. Blood 2014;124(18):2793-803.

[9] Arber DA, Orazi A, Hasserjian R, Thiele J, Borowitz MJ, Le Beau MM, et al. The 2016 revision to the World Health Organization classification of myeloid neoplasms and acute leukemia. Blood 2016;127(20):2391-405.

[10] Greenberg PL, Tuechler H, Schanz J, Sanz G, Garcia-Manero G, Solé F, et al Revised international prognostic scoring system (IPSS-R) for myelodysplastic syndrome. Blood 2012;120(12):2454-65.

[11] Olney HJ, Le Beau MM. Evaluation of recurring cytogenetic abnormalities in the treatment of myelodysplastic syndromes. Leukemia Res 2007;31: 427-34.

[12] Faramarz N, Nagesh R, Sophin S, Wayne W. Myelodysplastic syndrome/neoplasms-overview. In: Atlas of hematopathology: morphology, immunophenotype, cytogenetics, and molecular approaches. London: Academic Press; 2013. p. 111-27.

[13] Vardiman JW, Thiele J, Arber DA, Brunning RD, Borowitz MJ, Porwit A, et al. The 2008 revision of the World Health Organization (WHO) classification of myeloid neoplasms and acute leukemia: rationale and important changes. Blood 2009;114(5):937-51.

[14] Pujara KM, Bhalara RV, Dhruva GA. A study of bone marrow iron storage in hematological disorder. Int J Health Allied Sci 2014;3(4):221-4.

[15] Schoh C, Schnittger S, Bursch S, Gerstner D, Hochhaus A, Berger U, et al. Comparison of chromosome banding analysis, interphase and hypermetaphase-FISH, qualitative and quantitative PCR for diagnosis and follow up in chronic Myeloid Leukemia: A study on 350 cases. Leukemia 2002;16:53-9.

[16] Shaffer LG, McGowan-Jordan J, Schmid M, editors. ISCN (2013): an international system for human cytogenetic nomenclature. Karger: Basel, Switzerland; 2013.

[17] Rashid A, khurshid M, Shaikh U, Adill S. Chromosomal abnormalities in primary myelodysplastic syndrome. JCPSP 2014;24(9):632-5.

[18] EL Hussieny NM, Mohamed SA, Matter MM. Myelodysplastic syndrome: an Egyptian experience. J Blood Disord Transfus 2012;3:121. doi: https://doi.org/ 10.4172/2155-9864.1000121.

[19] Gmidene A, Sennana H, Fenaux P, Laatiri A, Zarrouk M, Bouaziz H, et al. Cytogenetic abnormalities in Tunisian de novo myelodysplastic syndrome: a comparison with other populations. Leukemia Res 2008;32:1824-9.
[20] Pozdnyakova O, Miron PM, Tang G, Walter O, Raza A, Woda B, et al. Cytogenetic abnormalities in a series of 1,029 patients with primary myelodysplastic syndromes: a report from the US with a focus on some undefined single chromosomal abnormalities. Cancer 2008;113:3331-40.

[21] Li L, Liu XP, Nie L, Yu M, Zhang Y, Oin T, et al. Unique cytogenetic features of primary myelodysplastic syndromes in Chinese patients. Leukemia Res 2009;33:1194-8.

[22] Chaubey R, Sazawal S, Dada R, Mahapatra M, Saxena R. Cytogenetic profile of Indian patients with de novo myelodysplastic syndromes. Indian J Med Res 2011;134:452-7

[23] Komorkji R. Myelodysplastic syndromes: a view where the sun rises and where the sun sets. Leukemia Res 2006:30:1067-8.

[24] Haase D, Germing U, Schanz J, Pfeilstöcker M, Nösslinger T, Hildebrandt B, et al. New insights into the prognostic impact of the karyotype in MDS and correlation with subtypes: evidence from a core dataset of 2124 patients. Blood 2007;110:4385-95.

[25] Giagounidis A, Haase D. Morphology, cytogenetics and classification of MDS. Best Pract Res Cl Ha 2013;26:337-53.

[26] Parlier V, Van Melle G, Beris P, Schmidt P, Tobler A, Bellomo M. Hematologic, clinical and cytogenetic analysis in 109 patients with primary myelodysplastic syndrome. Prognostic significance of morphology and chromosome findings. Cancer Genet Cytogenet 1994;78:219-31.

[27] Panani AD, Roussos C. Cytogenetic aspects of adult primary myelodysplastic syndromes clinical implications. Cancer Lett 2006;235:177-90.

[28] Toyoma K, Ohyashiki K, Yashida Y. Clinical implications of chromosomal abnormalities in 401 patients with myelodysplastic syndromes: a multicenter study in Japan. Leukemia 1993;7:499-508.

[29] Matsushima T, Handa H, Yokohama A, Nagasaki J, Koiso H, Kin Y, et al. Prevalence and clinical characteristics of myelodysplastic syndrome with bone marrow eosinophilia or basophilia. Blood 2003;101:3386-90.

[30] Matsuda A, Germing U, Jinnai I, Misumi M, Kuendgen A, Knipp S, et al. Difference in clinical features between Japanese and German patients with refractory anemia in myelodysplastic syndromes. Clin Trial Obs 2005;106:2633-40.

[31] Mhawech P, Saleem A. Myelodysplastic syndrome: review of cytogenetic and molecular data. Crit Rev Oncol Hematol 2001;40:229-38.

[32] Radivoyevitch R, Saunthararajah Y. Sex difference in myelodysplastic syndrome survival and balance in randomized clinical trials. J Clin Oncol 2014;32(1):60-1.

[33] Barrett EL, Richardson DS. Sex differences in telomeres and life span. Aging Cell 2011;10:913-21. 